\title{
AS FRAÇÕES NAS ARITMÉTICAS EDITADAS PARA AS ESCOLAS PAROQUIAIS LUTERANAS GAÚCHAS DO SÉCULO XX
}

\author{
Malcus Cassiano Kuhn* \\ Arno Bayer**
}

\begin{abstract}
Resumo: Em 1900, o Sínodo de Missouri, hoje Igreja Evangélica Luterana do Brasil, iniciou missão nas colônias alemãs do Rio Grande do Sul, fundando congregações religiosas e escolas paroquiais. $\mathrm{O}$ artigo discute o estudo das frações nas aritméticas editadas pela Igreja Luterana para suas escolas. A investigação documental está baseada no referencial da pesquisa histórica e no conceito de cultura escolar. Analisando-se as edições da Segunda e Terceira Aritmética da série Concórdia, verificou-se que nas edições da Segunda Aritmética se prioriza o significado de fração pelo método de ensino intuitivo. Na Terceira Aritmética se desenvolvem as habilidades de cálculo escrito e mental, com foco nos algoritmos e procedimentos de cálculo das quatro operações com frações. As propostas de estudo das frações estão contextualizadas com práticas socioculturais, desenvolvidas nas comunidades em que as escolas paroquiais luteranas estavam inseridas, associadas com unidades dos sistemas de medidas e operações comerciais.
\end{abstract}

Palavras-chave: História da Educação Matemática. Frações. Livros de Aritmética. Cultura Escolar.

\section{Introdução}

O Sínodo Evangélico Luterano Alemão de Missouri ${ }^{1}$, atualmente Igreja Evangélica Luterana do Brasil - IELB, iniciou missão nas colônias alemãs do Rio Grande do Sul - RS, fundando congregações religiosas e escolas paroquiais, em 1900. Conforme Kuhn e Bayer (2017b), as escolas paroquiais luteranas estavam inseridas num projeto missionário e comunitário que buscava ensinar a língua materna, Matemática, valores culturais, sociais e, principalmente, religiosos. Tais escolas:

Tinham uma responsabilidade para com a comunidade no sentido de, junto e com ela, promover o crescimento e o desenvolvimento pessoal de todos que a compõe,

\footnotetext{
* Malcus Cassiano Kuhn é Doutor em Ensino de Ciências e Matemática pela Universidade Luterana do Brasil ULBRA/Canoas/RS. Professor do Instituto Federal de Educação, Ciência e Tecnologia Sul-rio-grandense IFSul, Câmpus Lajeado/RS. Membro do Grupo de Pesquisas sobre Formação de Professores de Matemática. Líder do Grupo de Pesquisa sobre Estratégias de Ensino para Educação Básica e Profissional.

** Arno Bayer é Doutor em Ciências da Educação pela Universidade Pontifícia de Salamanca/Espanha. Professor e Pesquisador do Programa de Pós-Graduação em Ensino de Ciências e Matemática da Universidade Luterana do Brasil - ULBRA/Canoas/RS. Líder do Grupo de Pesquisas sobre Formação de Professores de Matemática.

${ }^{1}$ Em 1847, um grupo de imigrantes luteranos alemães da Saxônia fundou no estado de Missouri (Estados Unidos), o Sínodo Evangélico Luterano Alemão de Missouri, Ohio e Outros Estados, atualmente Igreja Luterana - Sínodo de Missouri.
} 
focando a cidadania. Se a escola formasse o ser humano com postura ética e moral exemplar, este poderia promover transformações sólidas em seu contexto social e seria um verdadeiro colaborador na seara de Deus e para o governo do mundo (KUHN; BAYER, 2017b, p. 132).

O Sínodo de Missouri também tinha uma preocupação acentuada em relação aos recursos didáticos usados nas escolas paroquiais, pois este material era escasso e a dificuldade era grande em manter um ensino planificado e organizado. Era necessário organizar o currículo das escolas e produzir material de acordo com a realidade brasileira. Conforme Weiduschadt (2007, p. 41), “os livros usados nas escolas paroquiais e utilizados pelos alunos foram produzidos pelas instituições religiosas com objetivo de formar e moldar as condutas e as práticas ao fazer a escolarização das comunidades". Dessa forma, por meio dos livros didáticos e dos periódicos pedagógicos, as escolas paroquiais luteranas gaúchas procuravam desenvolver uma educação integral cristã em todas as disciplinas.

Este artigo tem por objetivo discutir a abordagem das frações nas aritméticas editadas pela IELB, por meio da Casa Publicadora Concórdia ${ }^{2}$ de Porto Alegre, para as escolas paroquiais luteranas do século XX no RS. Trata-se de um recorte de tese, complementado por pesquisas realizadas durante o estágio Pós-doutoral em um Programa de Pós-Graduação.

O movimento migratório no estado gaúcho tem sido objeto de pesquisas. No âmbito da História da Educação no RS, os trabalhos de Kreutz (1991, 1994), Rambo (1994, 1996), Lemke (2001) e Weiduschadt $(2007,2012)$ são destaques. Na História da Educação Matemática no estado gaúcho, destacam-se as pesquisas de Mauro (2005), Wanderer (2007), Britto (2016), Kuhn e Bayer (2017a, 2017b). Como a temática investigada se insere na História da Educação Matemática no RS, busca-se na pesquisa histórica e no conceito de cultura escolar, o suporte para discussão.

Conforme Prost (2008), os fatos históricos são constituídos a partir de traços deixados no presente pelo passado. Assim, a tarefa do historiador consiste em efetuar um trabalho sobre esses traços para construir os fatos. Certeau (1982) define o fazer história, no sentido de pensar a história como uma produção. Para o autor, a história, como uma produção escrita, tem a tripla tarefa de convocar o passado que já não está em um discurso presente, mostrar as competências do historiador (dono das fontes) e convencer o leitor. O trabalho do historiador,

\footnotetext{
${ }^{2}$ Fundada em 1923, fazia a edição de livros e de periódicos relacionados à literatura religiosa e escolar da IELB. Foi a primeira e a única redatora da IELB, existente até os dias atuais. Antes de sua fundação, os livros e os periódicos eram impressos pela Concordia Publishing House, nos Estados Unidos, e enviados para o Brasil.
} 
de acordo com Certeau (1982), é fazer um diálogo constante do presente com o passado, e o produto desse diálogo consiste na transformação de objetos naturais em cultura.

Julia (2001) define a cultura escolar como um conjunto de normas que estabelecem conhecimentos a ensinar e condutas a inspirar, e um conjunto de práticas que permitem a transmissão desses conhecimentos e a incorporação desses comportamentos. Então, o estudo da cultura escolar instiga a busca pelas normas e finalidades que regem a escola, a avaliação do papel desempenhado pelo professor e a análise dos conteúdos ensinados e das práticas escolares. Chervel (1990) considera importante o estudo da cultura escolar para a compreensão dos elementos que participam da produção/elaboração/constituição dos saberes escolares e, em particular, da matemática escolar e sua história.

De acordo com Valente (2007), pensar os saberes escolares como elementos da cultura escolar e realizar o estudo histórico da matemática escolar, exige que se devam considerar os produtos dessa cultura no ensino, que deixaram traços que permitem o seu estudo, como as aritméticas da série Concórdia, principais fontes documentais desta investigação.

\section{$2 \mathrm{O}$ estudo das frações nas escolas paroquiais luteranas gaúchas do século XX}

Conforme estudos realizados por Kuhn e Bayer (2017a), nas escolas paroquiais luteranas gaúchas do século passado, o ensino da Matemática priorizava os números naturais, os sistemas de medidas, as frações e os números decimais, complementando-se com a matemática comercial e financeira e a geometria. O ensino desta disciplina deveria acontecer de forma prática e articulada com as necessidades dos futuros agricultores, observando-se a doutrina luterana. Segundo Lemke (2001), o ensino da palavra de Deus, através da Bíblia, ficava em primeiro lugar, e as demais disciplinas não eram menosprezadas, mas complementavam a educação para servir no mundo.

Embora, nas primeiras três décadas de existência dessas escolas, o material didático empregado para as aulas de Matemática tivesse origens diversas, identificaram-se orientações pedagógicas, publicadas pela imprensa ligada à Igreja Luterana, as quais defendiam a abordagem das frações pelo método de ensino intuitivo ${ }^{3}$, seguida de exercícios para o

\footnotetext{
${ }^{3}$ Método de ensino que surgiu na Alemanha no final do século XVIII e divulgado pelos discípulos de Pestalozzi no decorrer do século XIX, na Europa e nos Estados Unidos. No Brasil, fez parte das propostas de reformulação da instrução pública no final do Império, sendo Rui Barbosa responsável por sistematizar os princípios do método intuitivo em seus pareceres e por traduzir o manual, Lições de Coisas, de Calkins. No método intuitivo, a escola deveria ensinar coisas vinculadas à vida, utilizar os objetos como suporte didático e os sentidos para produção de ideias, iniciando do concreto e ascendendo à abstração. Os sentidos deveriam ser educados para obter o conhecimento, passando da intuição dos sentidos para a intuição intelectual.
} 
desenvolvimento de habilidades de cálculo mental e escrito de acordo com o nível dos alunos, e por fim, a aplicação prática do conhecimento matemático formalizado.

$\mathrm{Na}$ obra de Lindemann (1888), Amerikanisch-Lutherische Schul-Praxis (Práticas escolares para os luteranos americanos), editada pela Editora Concórdia de Sant Louis (Estados Unidos), o autor traz uma série de orientações pedagógicas para o ensino da Matemática nas escolas missourianas:

\begin{abstract}
Nas classes iniciais, não importa muito a aritmética escrita, mas que as crianças entendam intuitivamente a ideia dos números e do sistema decimal. Nos primeiros anos de escola será suficiente que as crianças compreendam os números de 1 a 1000 corretamente, saibam ler e escrever os números e executar os cálculos básicos envolvendo as quatro operações. Nos anos seguintes, devem aprender as quatro operações com todos os números e também os números decimais. Mais adiante, aprendem as frações comuns, unidades de medida, cálculos com preços e percentagem e a solução de tarefas geométricas simples. O treino e memorização de tabelas com unidades de medida, de pesos e moedas devem ser realizadas mais no final da escolarização. (LINDEMANN, 1888, p. 51, tradução nossa).
\end{abstract}

Essas orientações também influenciaram as escolas paroquiais luteranas gaúchas através dos pastores e professores vindos dos Estados Unidos e por aqueles formados, posteriormente, no Seminário Concórdia ${ }^{4}$ de Porto Alegre. Ainda conforme Lindemann (1888), o ensino das frações deveria acontecer com o uso de recursos visuais para ilustrar as diversas partes de um inteiro. Para isto, serveriam pedaços de madeira e outros materiais, disponíveis na época, que poderiam ser desmontados e montados novamente, além de desenhos para se desenvolver as ideias de metade, terça parte, quarta parte, etc..

Ao produzir o material didático para as escolas paroquiais, a IELB, através da Casa Publicadora Concórdia, procurou seguir essas orientações didáticas, editando e publicando duas séries para as aulas de Matemática: a série Ordem e Progresso, lançada na década de 1930, e a série Concórdia, lançada na década de 1940. Essas séries são compostas por três aritméticas voltadas para os primeiros anos de escolarização. No Instituto Histórico da IELB em Porto Alegre, localizaram-se a Primeira e a Terceira Aritmética, ambas da série Ordem e Progresso, e uma edição da Primeira, duas edições da Segunda e uma edição da Terceira Aritmética, todas da série Concórdia. Registra-se que ainda não foi localizada a Segunda Aritmética da série Ordem e Progresso.

Como as edições da Primeira Aritmética da série Ordem e Progresso e da série Concórdia somente possuem registros envolvendo os números naturais até 100 e a Terceira

\footnotetext{
${ }^{4}$ Instituto pedagógico-teológico que atuou na formação de pastores e professores sinodais para IELB.
} 
Aritmética da série Ordem e Progresso é semelhante à Terceira Aritmética da série Concórdia, abordando as mesmas unidades de estudo e exercícios, com o mesmo número de páginas e igual distribuição das mesmas para cada conteúdo na obra, havendo apenas variações na ortografia de palavras e na representação de unidades de medida e do sistema monetário ${ }^{5}$, esta investigação se restringe às duas edições da Segunda Aritmética e à edição da Terceira Aritmética, ambas da série Concórdia, brevemente apresentadas no Quadro 1:

Quadro 1 - Aritméticas analisadas.

\begin{tabular}{|c|c|c|c|}
\hline Obra & Data & Autor & Páginas \\
\hline Segunda Aritmética & {$[194-]$} & Otto A. Goerl $^{6}$ & 77 \\
\hline Segunda Aritmética & 1948 & Sem autoria declarada & 96 \\
\hline Terceira Aritmética & 1949 & Sem autoria declarada & 143 \\
\hline
\end{tabular}

Fonte: Série Concórdia.

$\mathrm{Na}$ análise das aritméticas elaboradas para as escolas paroquiais luteranas gaúchas do século XX, observou-se que a ideia de fração começa a ser desenvolvida nas edições da Segunda Aritmética, enquanto que as edições da Terceira Aritmética complementam o seu estudo de maneira formalizada.

\section{As frações nas edições da Segunda Aritmética da série Concórdia}

As duas edições da Segunda Aritmética trazem uma proposta de estudo para as frações, com foco na compreensão das relações parte-todo (quando um todo é dividido em partes iguais) e quociente (divisão de um número natural por outro diferente de zero). Exploram essas ideias de fração, dando ênfase para as frações $\frac{1}{2}, \frac{1}{4}$ e $\frac{1}{3}$. Na Figura 1, mostra-se como Otto Goerl inicia o estudo das frações, na Segunda Aritmética:

\footnotetext{
${ }^{5}$ Esta é a principal alteração observada nas duas edições, pois até 31 de outubro de 1942, a moeda brasileira era denominada réis, e a partir de $1^{\circ}$ de novembro de 1942 entrou em vigor o cruzeiro (Cr\$).

${ }^{6}$ O gaúcho Otto Adolpho Goerl (1905-1998) se formou no Seminário Concórdia, em 1925, e foi ordenado pastor em 1926. Além de pastor, foi professor paroquial e, posteriormente, professor e diretor do Seminário Concórdia. Autor de livros para o ensino de leitura e da aritmética nas escolas paroquiais luteranas. Também foi redator da revista teológica e pedagógica Igreja Luterana.
} 
Figura 1 - Sabem o que é $1 / 2,1 / 4,1 / 3$ ?

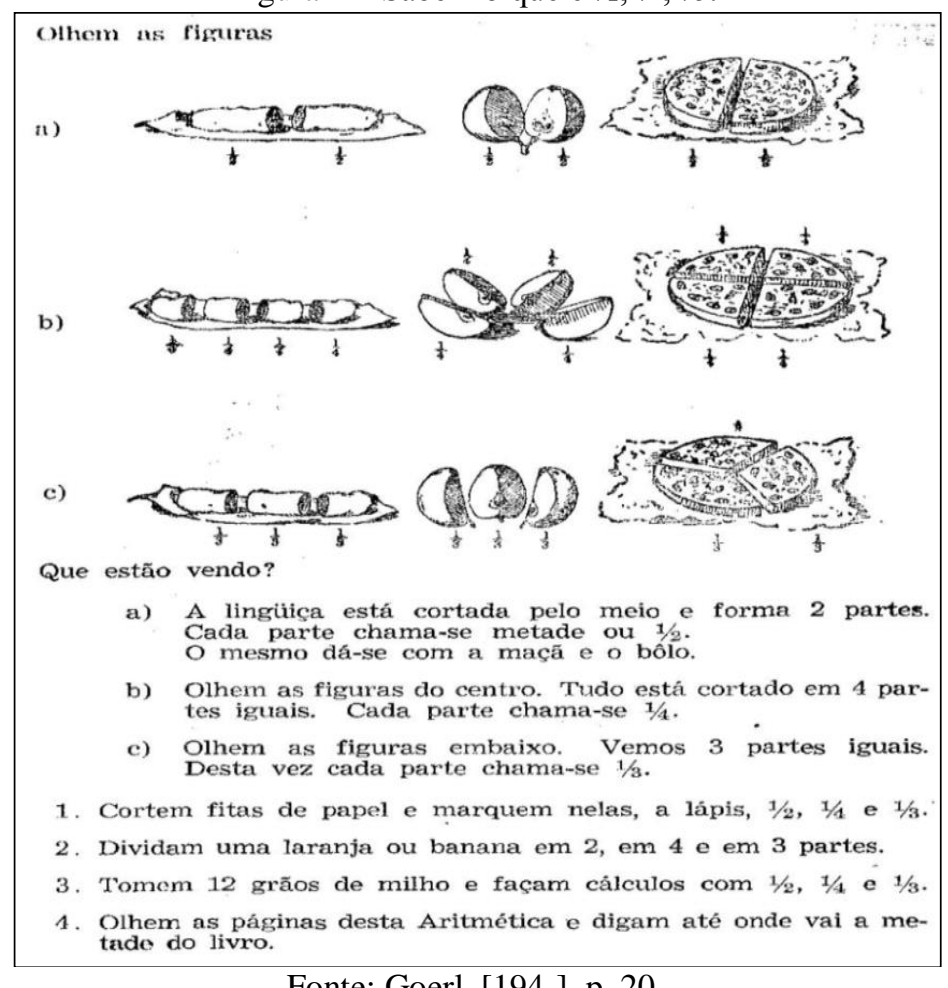

Fonte: Goerl, [194-], p. 20.

Conforme se observa, na Figura 1, o autor trabalha com a visualização da divisão de uma linguiça, uma maçã e um bolo em duas, quatro e três partes iguais, para desenvolver o significado de $\frac{1}{2}$ (metade), $\frac{1}{4}$ (quarta parte) e $\frac{1}{3}$ (terça parte), respectivamente. Em seguida, propõe quatro exercícios práticos para explorar a ideia de $\frac{1}{2}, \frac{1}{4}$ e $\frac{1}{3}$, evidenciando-se o emprego do método de ensino intuitivo.

Na sequência, o autor também explora a ideia de quociente das frações, como se pode observar na Figura 2: 
Figura 2 - Agora sabem o que é $1 / 2,1 / 4,1 / 3$ !

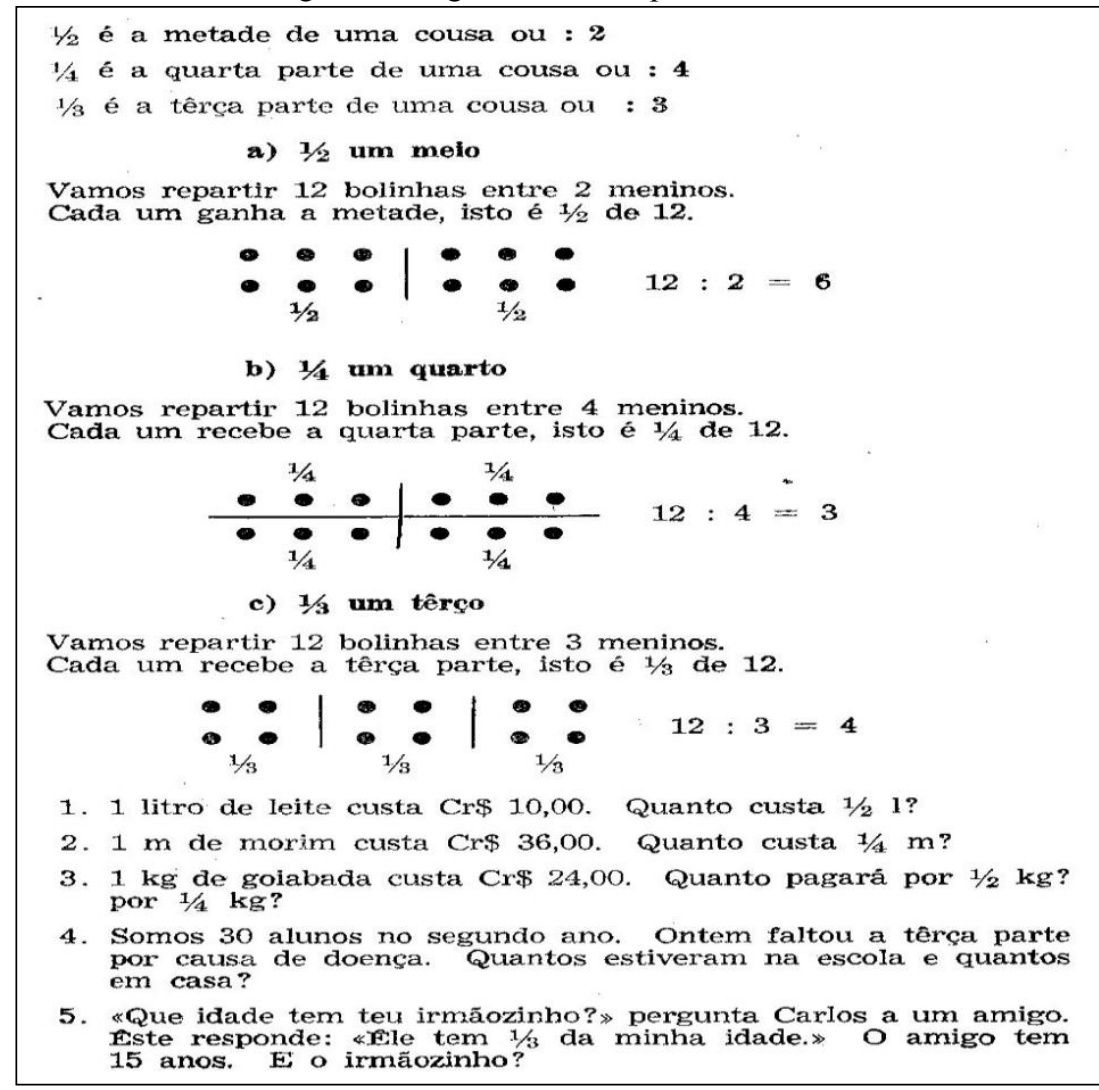

Fonte: Goerl, [194-], p. 21.

Para explorar o significado de quociente das frações, o autor associa as frações $\frac{1}{2}$ (metade) com a divisão por $2, \frac{1}{4}$ (quarta parte) com a divisão por 4 e $\frac{1}{3}$ (terça parte) com a divisão por 3, exemplificando com a divisão de 12 bolinhas, igualmente, entre 2, 4 e 3 meninos, respectivamente. Também são propostos cinco exercícios de aplicação do conteúdo desenvolvido, envolvendo, inclusive, unidades dos sistemas de medidas.

Goerl explora as ideias parte-todo e quociente das frações, em problemas relacionados com diferentes contextos, ao longo do livro, conforme excertos apresentados no Quadro 2:

Quadro 2 - Problemas envolvendo as ideias de fração.

1) Comprei $1 \frac{1}{2} \mathrm{~kg}$ de queijo. O kg custa $\mathrm{Cr} \$ 80,00$. Que troco recebi de 200 cruzeiros?

2) Berta foi comprar $2 \mathrm{dz}$ de ovos no armazém. Ela quebra alguns em caminho, e alguns estavam estragados. Disse a mãe: "Perdemos $1 / 3$ dos ovos". Quantos?

3) José tinha 640 mudas de violetas. Um freguês levou a metade e, pouco depois, outro freguês levou 1/4 do que sobrara. Quanto José vendeu de cada vez?

$$
\text { Fonte: Goerl, [194-]. }
$$

Os problemas, apresentados no Quadro 2, e os demais, encontrados nessa aritmética, somente envolvem as frações $\frac{1}{2}, \frac{1}{4}, \frac{1}{3}$ e alguns números mistos com estas frações. Observa- 
se que os problemas exploram as ideias de fração, parte-todo e quociente, estão relacionados com diferentes contextos e articulados com unidades dos sistemas de medidas e operações comerciais, mostrando consonância com as orientações pedagógicas da época.

Na Segunda Aritmética de 1948, o estudo das frações se inicia explorando a ideia de fração, parte-todo, relacionando o todo com um queijo que é fracionado em partes iguais, conforme observado na Figura 3:

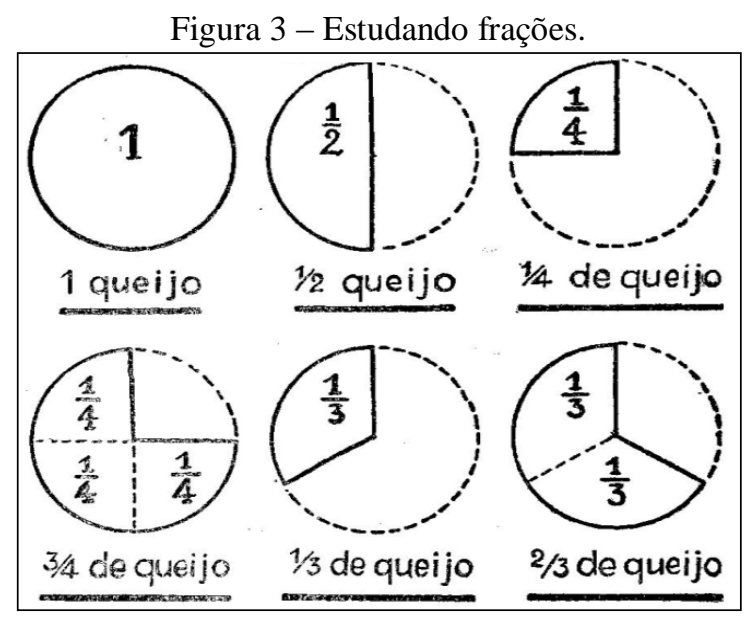

Fonte: Série Concórdia, 1948, p. 35.

Essa edição da Segunda Aritmética enfatiza o estudo das frações $\frac{1}{2}, \frac{1}{4}$ e $\frac{1}{3}$, trazendo uma proposta pedagógica que envolve um queijo com formato circular. Além da representação visualizada na Figura 3, o livro propõe ao aluno desenhar queijos e fazer a divisão em 2, 4 e 3 partes iguais, para desenvolver o significado de $\frac{1}{2}$ (meios), $\frac{1}{4}$ (quartos) e $\frac{1}{3}$ (terços), respectivamente. Na sequência do estudo, o livro traz a mesma representação visual das frações $\frac{1}{2}, \frac{1}{4}$ e $\frac{1}{3}$ em desenhos com linguiças, maçãs e bolos, conforme apresentado na Figura 1. Novamente, destaca-se o emprego do método intuitivo no estudo inicial das frações e a atenção dada para o significado e o emprego das frações $\frac{1}{2}, \frac{1}{4}$ e $\frac{1}{3}$.

O Quadro 3 apresenta um exercício envolvendo a elaboração de notas de compras, relacionadas com frações e números decimais: 
Quadro 3-Notas de compras.

\begin{tabular}{|c|c|c|c|}
\hline \multicolumn{3}{|c|}{ Tabela de preços } & Formar notas de compras: \\
\hline Carme die purco. & $\mathrm{kg} \quad \mathrm{Cr} \$$ & 1,60 & 1) $3 / 4 \mathrm{~kg}$ de salame, $1 / 2 \mathrm{~kg}$ de patê, $3 / 4 \mathrm{~kg}$ de peixe. \\
\hline Sottank & $\mathrm{kg}$ Cr\$ & 3,20 & 2) $2^{1 / 2} \mathrm{~kg}$ de salame, $31 / 4 \mathrm{~kg}$ de patê, $43 / 4 \mathrm{~kg}$ de peixe. \\
\hline l'até & $\mathrm{kg} \mathrm{Cr}_{\mathrm{T}} \mathrm{S}$ & 2,80 & \\
\hline P'eixe & $\mathrm{kg} \quad \mathrm{Cr} \$$ & 1,60 & \\
\hline Queijo & $\mathrm{kg} C r \$$ & 2,40 & \\
\hline
\end{tabular}

Fonte: Série Concórdia, 1948, p. 51.

O excerto, mostrado no Quadro 3, desafia o aluno a formar notas de compras de mercadorias a partir de uma tabela de preços com número decimais, explorando-se a ideia parte-todo das frações, para determinar o preço a pagar, na aquisição de cada mercadoria e, posteriormente, o preço total da nota. As atividades envolvendo as notas de compras estão relacionadas com práticas socioculturais desenvolvidas nas comunidades em que as escolas paroquiais luteranas gaúchas estavam inseridas. Conforme Dreher (1999), cada picada ${ }^{7}$ abrigava uma casa comercial, para a qual eram vendidos os excedentes de produção e adquiridos os bens não produzidos na comunidade.

O livro, ainda, traz outras atividades para explorar as ideias parte-todo e quociente, das frações, como a representação de frações por desenhos e exercícios envolvendo frações articuladas com as unidades dos sistemas de medidas. O Quadro 4 apresenta problemas envolvendo frações, encontrados na Segunda Aritmética de 1948:

Quadro 4 - Problemas com frações em contextos de administração do orçamento familiar.

1) A família Vargas paga aluguel duma casa, em $\frac{1}{2}$ ano, Cr $\$ 840,00 ;$ a família Barbosa paga em $\frac{1}{4}$ de ano só Cr\$195,00. Quanto paga cada família em 1 mês?

2) Nós precisamos diariamente de $\frac{1}{2} \mathrm{~kg}$ de pão e de $\frac{1}{2} \mathrm{~kg}$ de carne. Qual será a nossa despesa, durante o primeiro trimestre, sabendo-se que $1 \mathrm{~kg}$ de pão custa $\mathrm{Cr} \$ 1,20$ e $1 \mathrm{~kg}$ de carne $\mathrm{Cr} \$ 1,60$ ?

3) Um empregado tem um ordenado de $\mathrm{Cr} \$ 5400,00$ por ano. Ele gasta com víveres $\frac{3}{5}$, em roupa $\frac{1}{4} \mathrm{e}$ contribui para a caixa da comunidade com $\frac{1}{10}$. Quanto economiza em 1 ano? Em 5 meses? Em 10 anos?

Fonte: Série Concórdia, 1948.

Observa-se que os problemas, mostrados no Quadro 4, envolvem frações em contextos de economia familiar, explorando as ideias parte-todo e quociente, das frações. Dessa forma, estudando-se conhecimentos matemáticos, os alunos das escolas paroquiais luteranas gaúchas começavam a ter noções de administração do orçamento familiar.

\footnotetext{
${ }^{7}$ Organização social na qual se encontravam o templo (católico ou luterano, as confissões religiosas às quais pertenciam os imigrantes alemães), a escola, o cemitério, a residência do professor ou do padre/pastor, o salão de festas comunitárias e a casa comercial.
} 
Ao finalizar esta seção, destaca-se que, as duas edições da Segunda Aritmética da série Concórdia, trazem uma proposta de estudo para desenvolver o significado das frações, de forma intuitiva, e o seu emprego, dando-se ênfase para as frações $\frac{1}{2}, \frac{1}{4}$ e $\frac{1}{3}$.

\section{As frações na Terceira Aritmética da série Concórdia}

A Terceira Aritmética da série Concórdia amplia o estudo das frações, com especial atenção para as operações com frações. A segunda unidade de estudo dessa obra são as frações. Aborda-se a definição de fração, leitura, tipo de frações (própria, imprópria e número misto) e redução de frações (redução de números inteiros ou mistos a frações impróprias e vice-versa), amplificação de frações (frações equivalentes), simplificação das frações, adição e subtração das frações ordinárias com o mesmo denominador, adição e subtração das frações ordinárias com denominadores diferentes, multiplicação (o multiplicador é uma fração, o multiplicador é um número inteiro, multiplicação de fração por fração), divisão (o divisor é um número inteiro, o divisor é uma fração - dividir um inteiro por uma fração e dividir fração por fração), frações decimais e ordinárias (conversão de fração decimal em ordinária e viceversa). No Quadro 5, apresenta-se a proposta de estudo inicial para as frações, encontrada na Terceira Aritmética:

Quadro 5 - Preliminares sobre frações.

Frações ordinárias são partes da unidade.

Representam-se as frações por meio de dois números colocados um sobre o outro e separados por um traço.

Ler frações: Lê-se primeiro o numerador (o número superior) e depois o denominador (número inferior), acrescentando ao denominador a terminação "avos".

Excetuam-se os denominadores os denominadores 2, 3, 4, 5, 6, 7, 8, 9, 10, 100, 1000, etc., que se lêem: meio, terço, quarto, quinto, sexto, sétimo, oitavo, nono, décimo, centésimo, milésimo, etc.

Fração própria é aquela que tem o numerador menor que o denominador.

Exemplos: $\frac{3}{4}, \frac{2}{3}, \frac{8}{9}, \frac{7}{20}, \frac{99}{100}$.

Fração imprópria é aquela cujo numerador é maior que o denominador.

Exemplo: $\frac{3}{2}, \frac{5}{3}, \frac{11}{10}, \frac{278}{100}$.

Número misto é um número composto de um número inteiro e uma fração própria.

Por exemplo: $2 \frac{1}{2}, 5 \frac{3}{4}, 10 \frac{9}{10}, 2 \frac{20}{50}$.

Redução de números inteiros ou mistos a frações impróprias e vice-versa:

Dividir 1 queijo em 2 partes, em 3 partes, em 4 partes.

Quantos meios dão 3, 6, 7, 10, 15 inteiros?

Quantos terços dão 2, 5, 7, 9, 12 inteiros?

Quantos quartos dão 3, 4, 7, 9, 10, 20 inteiros? 
Uma vasilha contém $2 \frac{1}{4} \ell$ de leite. Quantos copos de $\frac{1}{4} \ell$ podem-se encher?

$2 \frac{1}{4}=\frac{9}{4} \quad \frac{9}{4}=2 \frac{1}{4}$

Fonte: Série Concórdia, 1949, p. 33-34.

A Terceira Aritmética apresenta uma proposta de estudo mais formalizada para as frações, conforme observado no Quadro 5. O excerto mostra que o livro apresenta uma definição para frações, seguindo com exemplos de leitura de frações e tipos de frações (própria, imprópria ${ }^{8}$ e número misto), com aplicações desse conteúdo. Observa-se o estudo da redução de frações, propondo a redução de números inteiros ou mistos a frações impróprias e vice versa, com exemplos e exercícios de aplicação, como a determinação do número de copos que podem ser cheios com a quantidade de litros de leite contidos numa vasilha.

O fragmento, apresentado no Quadro 6, mostra relações de equivalência de frações, a partir da divisão de queijos circulares em partes iguais:

Quadro 6 - Equivalência de frações ordinárias com queijos circulares.
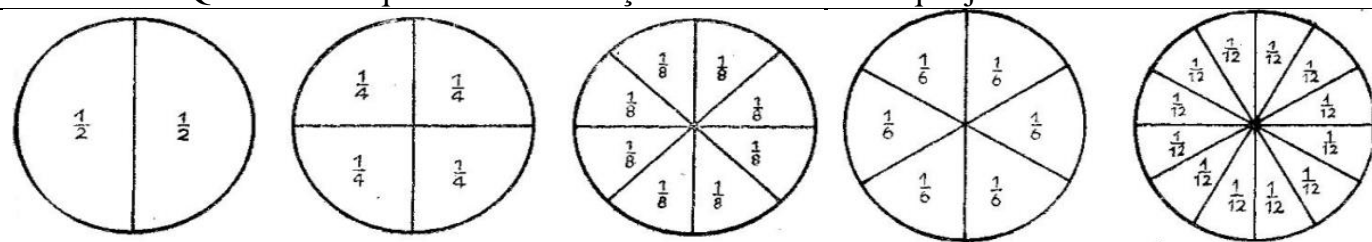

Dividir um queijo em 2 meios. Dividir cada meio em duas partes. Quantos quartos têm um meio? Dividir cada quarto em duas partes. Quantos oitavos têm um quarto?

$$
1=\frac{2}{2} \quad \frac{1}{2}=\frac{2}{4} \quad \frac{1}{2}=\frac{4}{8} \quad \frac{1}{4}=\frac{2}{8} \quad \frac{3}{4}=\frac{6}{8}
$$

Desenhar um queijo redondo. Dividir em duas partes. Dividir cada parte em três partes. Que parte do inteiro representa uma parte? Dividir cada sexto em 2 partes. Como se chama cada parte?

Fonte: Série Concórdia, 1949, p. 35.

Observa-se que o excerto explora as classes de equivalência de $\frac{1}{2}$ e $\frac{1}{3}$ através de representações geométricas circulares. A representação com queijos circulares, para esse estudo, pode estar relacionada com o fato de que os imigrantes alemães faziam queijos com forma circular em suas colônias, sendo um alimento conhecido dos alunos e sua representação

\footnotetext{
${ }^{8}$ Registra-se que a definição de fração imprópria, apresentada nessa aritmética, está incompleta, pois uma fração imprópria é aquela cujo numerador é maior ou igual ao denominador. No caso, $\frac{5}{5}$ e $\frac{8}{8}$ também são frações impróprias. Acrescenta-se que o livro não faz referência às frações aparentes, ou seja, aquelas cujo numerador é um múltiplo do denominador. Exemplo: $\frac{3}{3}, \frac{6}{2}, \frac{9}{1}$. Estas frações representam números naturais.
} 
familiar. A partir desta sistematização, o livro propõe exercícios de aplicação sobre frações equivalentes.

Para desenvolver a ideia de simplificação de frações, o livro propõe uma articulação com unidades de medida de tempo, conforme observado na Figura 4:

Figura 4 - Simplificação das frações.

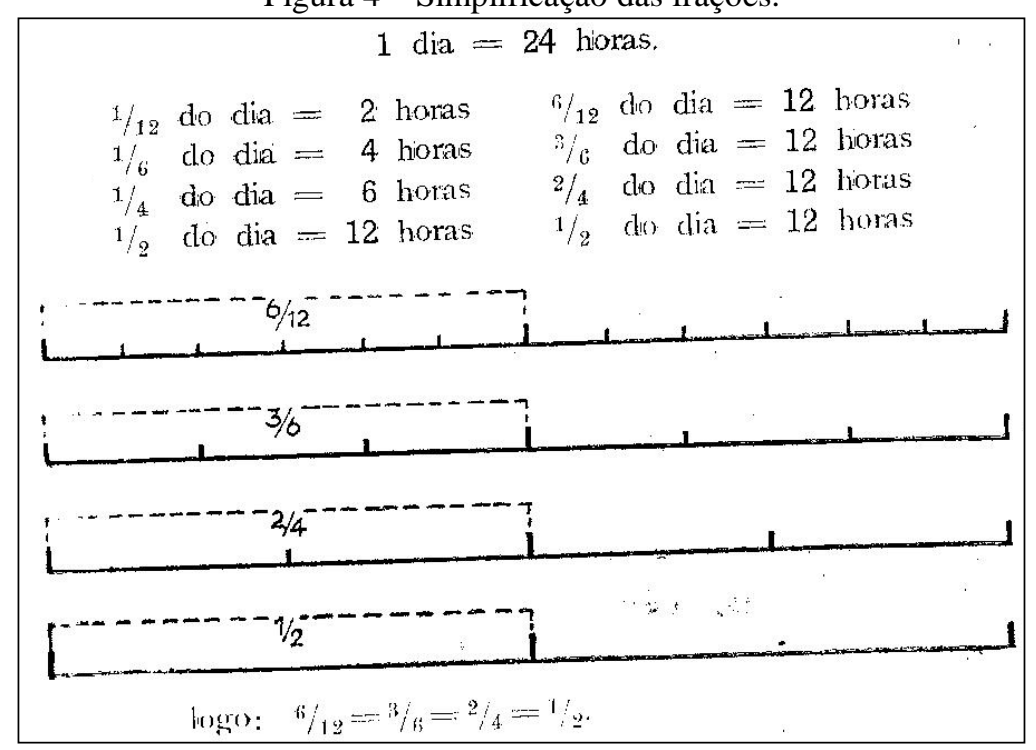

Fonte: Série Concórdia, 1949, p. 37.

A proposta do livro, apresentada na Figura 4, relaciona a simplificação de frações com as unidades de medida de tempo, dia e hora, possibilitando ao aluno fazer a associação do conhecimento matemático. Verifica-se, com a proposta apresentada no Quadro 6, que o livro desenvolve a ideia de que o valor de uma fração não muda, quando se multiplica o numerador e o denominador pelo mesmo número, e com a proposta, mostrada na Figura 4, o livro desenvolve a ideia de que o valor de uma fração não se altera, quando se divide o numerador e o denominador pelo mesmo número.

Na sequência, a Terceira Aritmética enfatiza as quatro operações com frações. A adição de frações com o mesmo denominador é desenvolvida com uma lista de exercícios envolvendo frações próprias e números mistos, sem qualquer explicação ou exemplo. $\mathrm{Na}$ subtração de frações com o mesmo denominador, essa aritmética apresenta o exemplo: $3-\frac{2}{3}=\frac{9}{3}-\frac{2}{3}=\frac{7}{3}=2 \frac{1}{3}$. Neste exemplo, o número inteiro é transformado numa fração imprópria com o mesmo denominador que o subtraendo para a resolução. No estudo da subtração de frações, ainda, é apresentado o exemplo: $10-\frac{2}{3}=9 \frac{1}{3}, 9 \frac{1}{3}-\frac{2}{3}=8 \frac{2}{3}, 8 \frac{2}{3}-\frac{2}{3}=8,8-\frac{2}{3}=$ etc. Observa-se que, partindo do 
inteiro 10, são feitas subtrações sucessivas da fração $\frac{2}{3}$. Como a maioria das escolas paroquiais luteranas gaúchas eram multisseriadas, ou seja, um único professor atendia mais de uma série na mesma sala de aula e no mesmo turno, exercícios como esse, ajudavam a manter uma série ocupada, enquanto o professor atendia as demais (KUHN; BAYER, 2017a).

A adição de frações, com denominadores diferentes, é introduzida pela proposta mostrada na Figura 5:

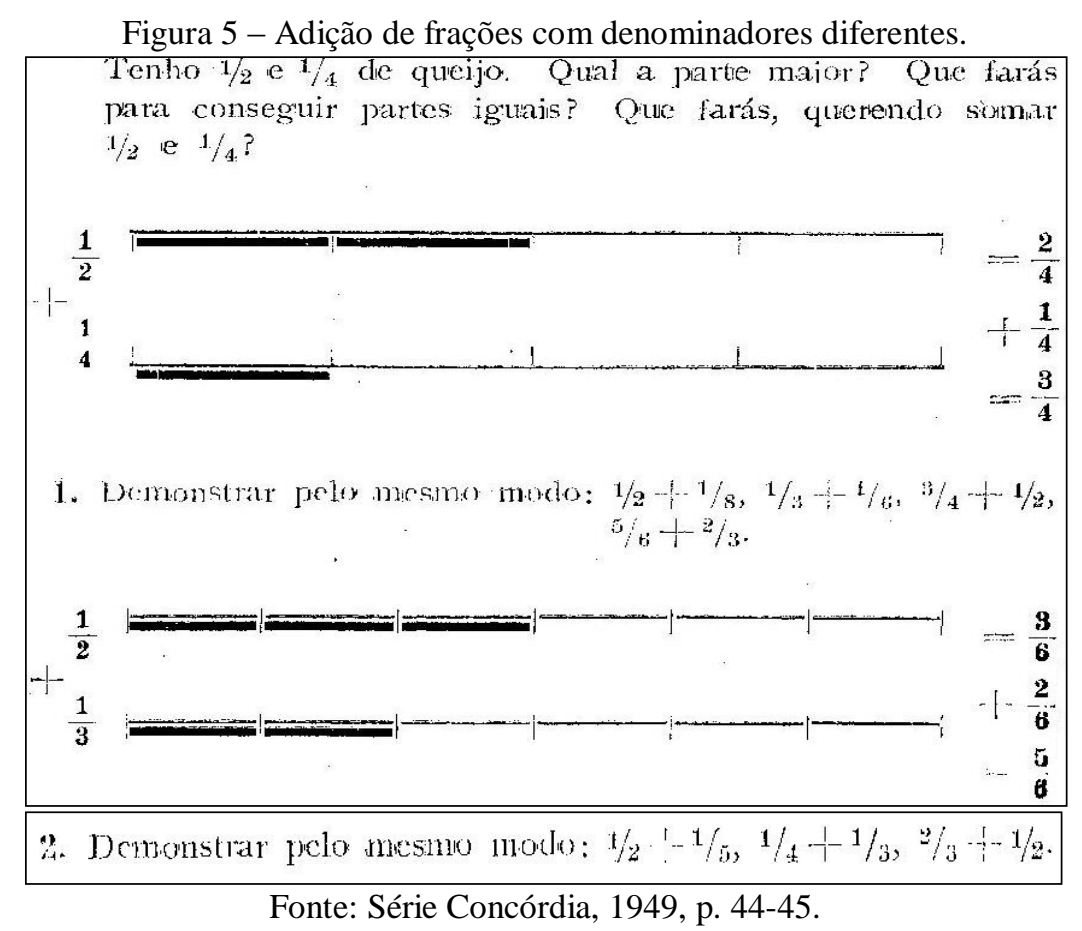

$\mathrm{Na}$ Figura 5, apresentam-se dois exemplos de redução de frações ao mesmo denominador, fazendo-se a demonstração pela equivalência de frações. Observa-se uma atenção ao algoritmo da redução de frações, embora, o procedimento da operação não esteja descrito. Na sequência do estudo, faz-se a redução de frações ao mesmo denominador pelo menor múltiplo comum (m. m. c.).

A proposta de estudo inicial para a subtração de frações, com denominadores diferentes, é ilustrada na Figura 6: 
Figura 6 - Subtração de frações com denominadores diferentes.

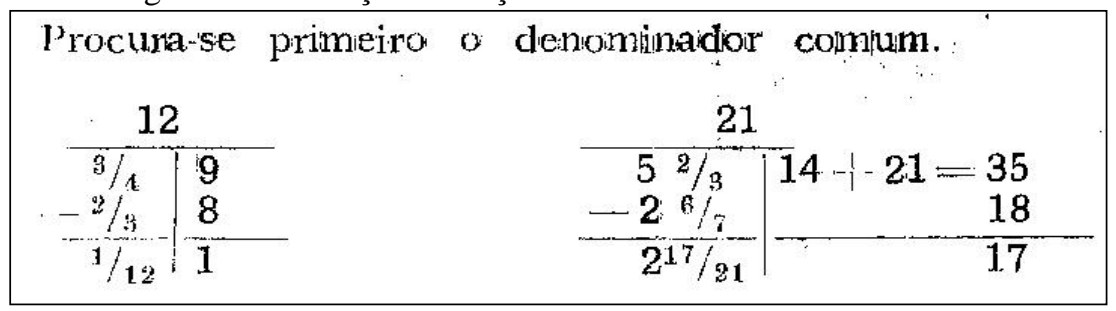

Fonte: Série Concórdia, 1949, p. 49.

O excerto, mostrado na Figura 6, traz dois exemplos de subtrações de frações com denominadores diferentes, através de um algoritmo que envolve a redução a frações com mesmo denominador pelo m. m. c.. No primeiro exemplo, 12 seria o m. m. c. de 4 e 3 , sendo a fração $\frac{3}{4}=\frac{9}{12}$ (multiplicando-se o numerador e o denominador da fração $\frac{3}{4}$ por 3 ) e a fração $\frac{2}{3}=\frac{8}{12}$ (multiplicando-se o numerador e o denominador da fração $\frac{2}{3}$ por 4 ), $\operatorname{logo}$ $\frac{3}{4}-\frac{2}{3}=\frac{9}{12}-\frac{8}{12}=\frac{1}{12}$. No segundo exemplo, $5 \frac{2}{3}-2 \frac{6}{7}$, a ideia inicial seria subtrair a parte inteira da parte inteira e a parte fracionária da parte fracionária, porém, como $\frac{2}{3}<\frac{6}{7}$ toma-se 1 inteiro dos 5 inteiros e transforma-se o mesmo na fração $\frac{21}{21}$, pois o m. m. c. de 3 e 7 é 21 . Considerando que $\frac{2}{3}=\frac{14}{21}$ e $\frac{6}{7}=\frac{18}{21}$, tem-se $5 \frac{2}{3}-2 \frac{6}{7}=4 \frac{35}{21}-2 \frac{18}{21}=2 \frac{17}{21}$.

O Quadro 7 apresenta a proposta de estudo para a multiplicação de frações na Terceira Aritmética:

Quadro 7 - Multiplicação de frações.

1) O multiplicador é uma fração:

a) Uma criança toma diariamente $\frac{3}{4}$ litros de leite. Quantos litros em uma semana?

$7 \times \frac{3}{4}=\frac{21}{4}=5 \frac{1}{4} \ell$

Nota: Multiplica-se o inteiro por uma fração pelo numerador da fração e dá-se ao produto o denominador dela.

2) O multiplicador é um número inteiro:

a) 1 litro de leite custa 80 centavos. Quanto gastarás comprando $\frac{1}{4}$ litro, $1 \frac{1}{2}$ litro?

$\frac{1}{4}$ de 80 centavos $=\frac{1}{4} \times 80=\frac{1 \times 80}{4}=20$ centavos

$1 \frac{1}{2}$ de 80 centavos $=\frac{3}{2} \times 80=\frac{3 \times 80}{2}=\operatorname{Cr} \$ 1,20$ 
b) $1 \mathrm{~m}$ de camisa custa $\mathrm{Cr} \$ 12,00$. Quanto custam $3 \frac{3}{4} \mathrm{~m}$ ?

$3 \frac{3}{4} \times 12=\frac{15}{4} \times 12=\frac{15 \times 12}{4}=\operatorname{Cr} \$ 45,00$

Nota: Multiplica-se uma fração por um número inteiro, multiplicando o numerador pelo número inteiro e dividindo o produto pelo denominador.

3) Multiplicação de fração por fração:

a) Uma garrafa contém $\frac{3}{4}$ litro de vinho. Quanto contém meia garrafa?

$\frac{1}{2}$ de $\frac{3}{4}=\frac{3}{4 \times 2}=\frac{3}{8}$

b) Um garrafão contém $4 \frac{1}{4}$ litros de vinagre. Gasta-se $\frac{1}{3}$. Calcular os $\frac{2}{3}$ que ficam no garrafão.

$\frac{2}{3} \times 4 \frac{1}{4}=\frac{2}{3} \times \frac{17}{4}=\frac{\frac{1}{2 \times 17}}{3 \times 4}=\frac{17}{6}=17 \div 6=2 \frac{5}{6}$

Nota: Multiplica-se uma fração por outra, multiplicando o numerador pelo numerador e o denominador pelo denominador. (Simplificar se for possível).

Fonte: Série Concórdia, 1949, p. 50-54.

A operação de multiplicação de frações é desenvolvida através de três casos: o multiplicador é uma fração, o multiplicador é um número inteiro e a multiplicação de fração por fração, conforme observado no Quadro 7. Em cada caso, o estudo é iniciado por exemplos com os algoritmos de cálculo envolvendo frações próprias, números inteiros e números mistos, contextualizados com unidades dos sistemas de medidas e operações comerciais. Nos algoritmos apresentados, sempre que possível, observa-se a simplificação de frações. Após os exemplos de cada caso, apresenta-se uma nota com a regra prática para os cálculos envolvendo a multiplicação de frações. Entre os vários exercícios propostos, envolvendo a multiplicação de frações, encontrou-se a tabuada com frações, descrita no Quadro 8:

Quadro 8 - Tabuada com frações.

\begin{tabular}{|c|c|c|c|}
\hline $\begin{array}{c}\text { 1) } 1 \times \frac{2}{3}=\frac{2}{3} \\
2 \times \frac{2}{3}=\frac{4}{3}=1 \frac{1}{3}\end{array}$ & $2 \times \frac{5}{6}=$ & $2 \times 2 \frac{1}{4}=$ & $2 \times 1 \frac{1}{8}$ \\
até & até & até & a) $1 \times 2 \frac{1}{4}=2 \frac{1}{4}$ \\
$10 \times \frac{2}{3}=$ & $10 \times \frac{5}{6}=$ & $10 \times 2 \frac{1}{4}=$ & $10 \times 1 \frac{1}{8}=$ \\
\hline
\end{tabular}

Fonte: Série Concórdia, 1949, p. 51. 
O Quadro 8 apresenta uma proposta com quatro exercícios de tabuada com as frações $\frac{2}{3}, \frac{5}{6}, 2 \frac{1}{4}$ e $1 \frac{1}{8}$. Ressalta-se que as atividades também envolvem números mistos com a representação de frações impróprias como números mistos e vice versa. Esse tipo de exercício reforça a ideia de que no ensino da Matemática, nas escolas paroquiais luteranas gaúchas do século passado, havia uma forte preocupação com o desenvolvimento de habilidades para o cálculo escrito e mental.

A proposta pedagógica para a operação de divisão de frações é desenvolvida de forma semelhante à multiplicação de frações, conforme observado no Quadro 9:

Quadro 9-Divisão de frações.

1) O divisor é um número inteiro:

a) Uma tábua tem um comprimento de $1 \frac{3}{5} \mathrm{~m}$; dividi-la em 2 partes iguais.

$1 \frac{3}{5} \div 2=\frac{8 \div 2}{5}=\frac{4}{5}$

Nota: Divide-se uma fração por um número inteiro, dividindo o numerador pelo número inteiro.

b) Repartir $\frac{1}{4}$ de uma cuca redonda entre 2 meninos. Quantas partes farás de $\frac{1}{4}$ ? Como se chama cada pedaço? $\frac{1}{4} \div 2=\frac{1}{4} \div \frac{2}{1}=\frac{1}{4} \times \frac{1}{2}=\frac{1 \times 1}{4 \times 2}=\frac{1}{8}$

Nota: Se o numerador não for divisível exatamente pelo número inteiro, multiplica-se o denominador pelo inteiro. 2) Divisão de um inteiro por uma fração:

a) Numa garrafa cabem $\frac{2}{3}$ litros. Quantas garrafas podem-se encher com 6 litros?

$$
\frac{2}{3} \times ?=6 \quad 6 \div \frac{2}{3}=6 \times \frac{3}{2}=\frac{18}{2}=9 \quad \frac{2}{3} \times 9=\frac{18}{3}=6
$$

b) Para uma camisa precisa-se de $2 \frac{1}{2} \mathrm{~m}$. Quantas camisas podem-se fazer de $15 \mathrm{~m}$ ?

Para saber quantas vezes estão contidos $2 \frac{1}{2} \mathrm{~m}$ em $15 \mathrm{~m}$, divide-se 15 por $2 \frac{1}{2}$.

$15 \div 2 \frac{1}{2}=15 \div \frac{5}{2}=\frac{3}{\frac{3}{5} \times 2}=6$

Nota: Divide-se um número inteiro por uma fração, multiplicando o número inteiro pela fração invertida.

3) Divisão de fração por uma fração:

a) Quantos copos de leite de $\frac{1}{4}$ de litro podem se encher com $\frac{1}{2}$ litro?

Quantas vezes está contido $\frac{1}{4}$ em $\frac{1}{2}$ ? Quantos quartos fazem $\frac{1}{2}$ ?

$\frac{1}{2}=? \times \frac{1}{4} \quad \frac{1}{2} \div \frac{1}{4}$

$\frac{2}{4}=2 \times \frac{1}{4} \quad \frac{2}{4} \div \frac{1}{4}=2$, pois $2 \times \frac{1}{4}=\frac{2}{4}=\frac{1}{2}$ 
b) Para uma camisa de criança precisam-se $\frac{4}{5} \mathrm{~m}$ de fazenda. Quantas camisas fazem-se com $3 \frac{1}{4} \mathrm{~m}$ ? Quantas vezes estão contidos $\frac{4}{5}$ em $3 \frac{1}{4}$ ?

$3 \frac{1}{4} \div \frac{4}{5}=\frac{13}{4} \div \frac{4}{5}=\frac{13}{4} \times \frac{5}{4}=\frac{13 \times 5}{4 \times 4}=\frac{65}{16}=65 \div 16=4 \frac{1}{16}$

Nota: Divide-se uma fração por uma fração, multiplicando o dividendo pelo divisor invertido.

\section{Fonte: Série Concórdia, 1949, p. 55-60.}

O estudo da operação de divisão de frações, também, é desenvolvido através de três casos: o divisor é um número inteiro, a divisão de um inteiro por uma fração e a divisão de fração por fração, de acordo com o Quadro 9. Nos três casos, o estudo é iniciado por exemplos com os algoritmos de cálculo envolvendo frações próprias, números inteiros e números mistos, contextualizados com unidades dos sistemas de medidas. Após os exemplos de cada caso, apresenta-se uma nota com a regra prática para os cálculos envolvendo a divisão de frações. Destaca-se o foco nos algoritmos e procedimentos de cálculo da divisão de frações, explorando-se a divisão e a multiplicação como operações inversas.

O Quadro 10 apresenta alguns problemas envolvendo as operações com frações, em diferentes contextos:

Quadro 10 - Problemas envolvendo operações com frações.

1) $\mathrm{O}$ alfaiate precisa para um terno $3 \frac{1}{4} \mathrm{~m}$ de fazenda, para uma calça $1 \frac{1}{4} \mathrm{~m}$, para um colete $\frac{2}{5} \mathrm{~m}$, para um sobretudo $2 \frac{1}{2} \mathrm{~m}$, para uma fatiota de menino $2 \frac{1}{4} \mathrm{~m}$.

a) Quanto precisa o alfaiate para um terno com mais uma calça e mais um colete?

b) Quanto precisa o alfaiate para um terno, para um sobretudo e para uma fatiota de menino?

c) Um alfaiate faz uma calça, duas fatiotas de menino, um terno para homem e ainda um colete. Quantos metros precisa?

d) O pai manda fazer para si um terno com duas calças e fatiotas para os seus três filhos. Quantos metros precisa comprar?

2) Um pedestre chegou a seu destino às $12 \frac{1}{2}$ horas, tendo caminhado $2 \frac{3}{4}$ horas. A que horas saiu?

3) "Como foi a colheita de milho neste ano?" perguntou um colono a seu vizinho. "Muito boa, colhi $\frac{1}{3}$ mais do que no ano passado." Quantos sacos colheu o vizinho, tendo colhido no ano passado $137 \frac{1}{2}$ sacos?

4) Uma vaca deu numa semana $25 \frac{1}{2}$ litros de leite. Quanto por dia?

5) Numa lâmpada de querosene cabem $\frac{3}{4}$ litros. Quantas vezes pode-se encher a lâmpada com uma lata de 17 litros?

Fonte: Série Concórdia, 1949.

Os cinco problemas, observados no Quadro 10, envolvem as operações com frações. O primeiro pode ser resolvido com adição de frações e o segundo problema envolve uma 
subtração de frações. O terceiro problema está relacionado com a operação de multiplicação e os dois últimos problemas envolvem a divisão com frações. Os problemas apresentados estão relacionados com as unidades dos sistemas de medidas e contextualizados com práticas socioculturais desenvolvidas nas comunidades em que as escolas paroquiais luteranas estavam inseridas, como a produção agrícola e a produção leiteira, além de vestuário e iluminação com lâmpadas de querosene.

Depois de uma proposta de estudo sistematizada das quatro operações com frações, as edições da Terceira Aritmética fazem uma recapitulação sobre as frações, apresentando as regras e exemplos para as quatro operações, além de exercícios, sem contextualização, envolvendo essas operações. Para finalizar o estudo das frações, a Terceira Aritmética apresenta regras para transformação de uma fração decimal em fração ordinária e vice versa. Ressalta-se que a proposta pedagógica dessa aritmética traz, inicialmente, o estudo das frações decimais, articuladas com as unidades dos sistemas de medidas, e, posteriormente, o estudo das frações ordinárias.

\section{Considerações finais}

Com este estudo histórico sobre as frações nas aritméticas editadas pela IELB, por meio da Casa Publicadora Concórdia, para as escolas paroquiais luteranas gaúchas do século XX, pretende-se contribuir para a História da Educação Matemática. Tendo por base o referencial da pesquisa histórica e o conceito de cultura escolar, investigaram-se duas edições da Segunda Aritmética e uma edição da Terceira Aritmética, editadas na década de 1940 e pertencentes à série Concórdia.

$\mathrm{Na}$ abordagem das frações, observou-se que as edições da Segunda Aritmética da série Concórdia priorizam o estudo do significado e emprego das frações $\frac{1}{2}, \frac{1}{3}$ e $\frac{1}{4}$, desenvolvendo as ideias parte-todo e quociente, de forma intuitiva e de acordo com as orientações pedagógicas da época.

A edição da Terceira Aritmética amplia o estudo das frações, abordando a equivalência de frações, a simplificação de frações e as quatro operações envolvendo as frações. Ressalta-se que os exemplos e os exercícios propostos procuram desenvolver as habilidades de cálculo escrito e mental, com foco nos algoritmos e procedimentos de cálculo das quatro operações envolvendo as frações. Também se observou que o estudo das frações 
ordinárias é realizado após o estudo das frações decimais, diferentemente do que acontece na Educação Básica, atualmente.

Por fim, acrescenta-se que nas aritméticas da série Concórdia, verificaram-se propostas de estudo das frações em contextos de práticas socioculturais desenvolvidas nas comunidades em que as escolas paroquiais luteranas gaúchas estavam inseridas, relacionadas, principalmente, com unidades dos sistemas de medidas e operações comerciais, o que estava de acordo com as orientações pedagógicas da época. Portanto, as práticas socioculturais foram mobilizadas para a sala de aula na formação educacional dos futuros colonos, especialmente, com a abordagem de atividades relacionadas à agricultura e à economia, evidenciando-se suas influências no ensino da Matemática.

\title{
THE FRACTIONS IN THE ARITHMETIC EDITED TO THE GAUCHO LUTHERAN PAROCHIAL SCHOOLS OF THE $20^{\text {TH }}$ CENTURY
}

\begin{abstract}
In 1900, the Missouri Synod, today Evangelical Lutheran Church of Brazil, began mission in the German colonies of Rio Grande do Sul, founding religious congregations and parochial schools. The article discusses the study of the fractions in the arithmetic edited by Lutheran Church to their schools. The documentary investigation is basing on history research and on concept of school culture. Analyzing the editions of the Second and Third Arithmetic of the Concordia series, there was that in the editions of the Second Arithmetic to prioritize the meaning of fraction by intuitive teaching method. In the Third Arithmetic develop the mental and written calculation skills, focusing on algorithms and calculation procedures of the four operations with fractions. The proposals of study of the fractions are contextualized with socio-cultural practices developed in the communities where the Lutheran parochial schools were included, associated with units of measures systems and commercial operations.
\end{abstract}

Keywords: History of the Mathematic Education. Fractions. Arithmetic Books. School Culture.

\section{Referências}

BRITTO, Silvio Luiz Martins. O ensino da aritmética nas escolas paroquiais católicas e no Ginásio Conceição, sob a ótica dos jesuítas nos séculos XIX e XX. 2016. 464 f. Tese (Doutorado em Ensino de Ciências e Matemática) - Universidade Luterana do Brasil, ULBRA, Canoas, 2016.

CERTEAU, Michel de. A escrita da História. Tradução Maria de Lourdes Menezes. Rio de Janeiro: Forense Universitária, 1982.

CHERVEL, André. História das disciplinas escolares - reflexões sobre um campo de pesquisa. Teoria \& Educação, Porto Alegre, RS, n. 2, p. 177-229, 1990. 
DREHER, Martin Norberto. O desenvolvimento econômico do Vale do Rio dos Sinos. Estudos Leopoldenses - Série História, v. 3, n. 2, p. 49-70, 1999.

GOERL, Otto Adolpho. Série Concórdia: Segunda Aritmética. Porto Alegre: Casa Publicadora Concórdia, [194-].

JULIA, Dominique. A cultura escolar como objeto histórico. Revista Brasileira de História da Educação, Campinas, SP, n. 1, p. 9-43, jan./jun. 2001.

KREUTZ, Lúcio. Material didático e currículo na escola teuto-brasileira. São Leopoldo: UNISINOS, 1994.

O professor paroquial: magistério e imigração alemã. Porto Alegre: Ed. da UFRGS; Caxias do Sul: EDUCS, 1991.

KUHN, Malcus Cassiano; BAYER, Arno. A matemática nas escolas paroquiais luteranas gaúchas do século XX. Canoas: ULBRA, 2017a.

$O$ contexto histórico das escolas paroquiais luteranas gaúchas do século $\mathrm{XX}$. Canoas: ULBRA, $2017 \mathrm{~b}$.

LEMKE, Marli Dockhorn. Os princípios da educação cristã luterana e a gestão de escolas confessionárias no contexto das ideias pedagógicas no sul do Brasil (1824 - 1997). Canoas: ULBRA, 2001.

LINDEMANN, Johann Christoph Wilhelm. Amerikanisch-Lutherische Schul-Praxis. 2. ed. Sant Louis: Lutherischer Concordia - Verlag, 1888.

MAURO, Suzeli. Uma história da matemática escolar desenvolvida por comunidades de origem alemã no Rio Grande do Sul no final do século XIX e início do século XX. 2005. 257 f. Tese (Doutorado em Educação Matemática) - Universidade Estadual Paulista, Rio Claro, 2005.

PROST, Antoine. Doze lições sobre a História. Belo Horizonte: Autêntica, 2008.

RAMBO, Arthur Blásio. A escola comunitária teuto-brasileira católica. São Leopoldo: UNISINOS, 1994.

A escola comunitária teuto-brasileira católica: a associação de professores e a escola normal. São Leopoldo: UNISINOS, 1996.

SÉRIE Concórdia: Segunda Aritmética. Porto Alegre: Casa Publicadora Concórdia, 1948.

SÉRIE Concórdia: Terceira Aritmética. Porto Alegre: Casa Publicadora Concórdia, 1949.

VALENTE, Wagner Rodrigues. História da Educação Matemática: interrogações metodológicas. REVEMAT - Revista Eletrônica de Educação Matemática, Florianópolis, SC, v. 2, n. 2, p. 28-49, 2007. 
WANDERER, Fernanda. Escola e Matemática Escolar: mecanismos de regulação sobre sujeitos escolares de uma localidade rural de colonização alemã no Rio Grande do Sul. 2007. 228 f. Tese (Doutorado em Educação) - Universidade do Vale do Rio dos Sinos, São Leopoldo, 2007.

WEIDUSCHADT, Patrícia. A revista "O Pequeno Luterano" e a formação educativa religiosa luterana no contexto pomerano em Pelotas - RS (1931-1966). 2012. $273 \mathrm{f}$. Tese (Doutorado em Educação) - Universidade do Vale do Rio dos Sinos, São Leopoldo, 2012.

O Sínodo de Missouri e a educação pomerana em Pelotas e São Lourenço do Sul nas primeiras décadas do século XX: identidade e cultura escolar. 2007. 255 f. Dissertação (Mestrado em Educação) - Universidade Federal de Pelotas, Pelotas, 2007. 